\title{
COMPORTAMENTO DE ONDAS ULTRASSÔNICAS EM PAINÉIS DE ALVENARIAS HISTÓRICAS COM PRESENÇA DE FISSURAS EM ARGAMASSA DE REVESTIMENTO
}

\author{
ARAUJO, EMANUEL \\ Aluno de Graduação \\ UFC - Russas / LAREB \\ Ceará; Brasil \\ emanuhenriqcivil@gmail.com \\ BESSA, MAYCON
Aluno de Graduação
UFC - Russas / LAREB
Ceará; Brasil
mayconbessa2014@ hotmail.com
}

\author{
SOUSA, ISRAEL \\ Aluno de Graduação \\ UFC - Russas / LAREB \\ Ceará; Brasil \\ israelnlsousa@gmail.com
}

SOEIRO, MARCOS
Professor, Mestre
UNIFOR / LAREB
Ceará; Brasil
marcos@ duosestruturais.eng.br

\author{
RODRIGUES, TÁLISSON \\ Aluno de Graduação \\ UFC - Russas / LAREB \\ Ceará; Brasil \\ talisson.ecivil@alu.ufc.br \\ MESQUITA, ESEQUIEL \\ Professor, $\mathrm{PhD}$ \\ UFC - Russas / LAREB \\ Ceará; Brasil \\ emesquita@ufc.br
}

\section{RESUMO}

Devido ao elevado valor cultural, variabilidade e complexidade dos sistemas estruturais, construções históricas tornaram-se um interessante e desafiador campo para o desenvolvimento de novas técnicas para caracterização e avaliação estrutural. Neste trabalho, foram realizados ensaios ultrassônicos pelo método indireto em painéis de alvenaria de uma igreja do século XVIII situada em Icó, Ceará, Brasil. O principal objetivo deste trabalho foi verificar o comportamento das ondas ultrassônicas pelo método indireto em painéis de alvenaria com a presença de fissuras na argamassa de revestimento, para o estabelecimento de uma correlação entre estes. Para tal análise foi aplicada uma metodologia baseada em medições ultrassônicas indiretas, em 16 painéis de alvenaria situados na edificação. Os resultados mostram que a utilização do ultrassom pelo método indireto é uma técnica promissora para detecção de danos, essencialmente fissuras, em painéis argamassados.

Palavras-chave: Caracterização não destrutiva, Ultrassom, Método indireto, Painel de alvenaria.

\section{ABSTRACT}

Due to the high cultural value, variability and complexity of structural systems, historic constructions have become an interesting and challenging field for the development of new techniques for structural characterization and evaluation. In this work, ultrasonic tests were carried out by the indirect method on masonry panels of an 18th century church located in Icó, Ceará, Brazil. The main objective of this work was to verify the behavior of ultrasonic waves by the indirect method in masonry panels with the presence of cracks in the coating mortar, to establish a correlation between them. For this analysis, a methodology based on indirect ultrasonic measurements was applied to 16 masonry panels located in the building. The results show that the use of ultrasound by the indirect method is a promising technique for detecting damage, essentially cracks, in mortar panels.

Keywords: Non-destructive characterization, Ultrasound, Indirect method, Masonry panel.

\section{INTRODUÇÃO}

Devido a variabilidade e complexidade de seus materiais componentes, as edificações históricas constituem um interessante desafio para o meio técnico-científico. Nos últimos anos vem-se observando uma elevação no número de ocorrência de desastres naturais (MUNICH RE, 2016), que podem comprometer a durabilidade do edificado. A ocorrência destes fenômenos associados ao desconhecimento sobre os materiais e propriedades de seus componentes, fazem da caracterização de edificações históricas um objeto de grande interesse mundial pois, por meio desta, é possível caracterizar as propriedades dos materiais e sistemas construtivos possibilitando o entendimento de seu comportamento global. E que, de um modo mais efetivo, podem resultar na elaboração de abordagens para fins de reabilitação do edificado patrimonial (BOSCATO et al., 2016; CERAVOLO et al., 2014; MESQUITA et al., 2018). 
As edificações histórias apresentam uma peculiaridade quando se trata de intervenção. De modo geral, elas precisam manter suas características originais e com respeito à identidade da sociedade a qual ela se insere. Dessa forma, deve-se realizar uma escolher criteriosa das estratégias de intervenção a se adotar, tendo em consideração tanto a escala da intervenção, quanto as suas diferentes fases. Portanto, a fase de caracterização experimental pode ser uma ferramenta de decisão para a conservação e o nível de intensidade da reabilitação.

Para a escolha das atividades necessárias no contexto da reabilitação das edificações, profundas investigações sobre o estado da estrutura devem ser realizadas. Dada a necessidade de mínima intrusão na construção avaliada, o método de avaliação deve recorrer às técnicas não destrutivas sempre que possível, de modo a preservar o máximo de características possíveis. Nesse sentido, os ensaios não destrutivos (END) se caracterizam como uma ótima ferramenta para avaliação da integridade de construções históricas, uma vez que causam pouco ou nenhum dano à estrutura analisada (ALVES, 2017).

Dentre os END existentes, destaca-se o ensaio de determinação de velocidade de pulso ultrassônico (VPU). Os testes sônicos são os mais aplicados em todo o mundo para caracterizar as propriedades das paredes de alvenaria. Na verdade, a caracterização de alvenarias é sempre uma tarefa difícil devido à sua variabilidade de tipologias e propriedades anisotrópicas (Miranda, 2011). Nos últimos anos, uma série de avanços no âmbito da utilização de ensaios ultrassônicos com aplicações em alvenarias foram feitos, desde o emprego do ultrassom para se identificar a heterogeneidade de alvenarias históricas, conforme reportado em Mesquita (2018), como a aplicação para estimativa de parâmetros mecânicos das alvenarias, conforme reportado por Martini (2019) e Miranda (2011). Todavia, ainda há uma série de questões que precisam ser investigadas, como por exemplo: 1) Como os ensaios ultrassônicos podem ser utilizados para avaliação da qualidade de revestimentos de alvenarias? 2) Como os vazios, imperfeições, temperatura, umidade e carregamento podem influenciar a propagação das ondas ultrassônicas? E, finalmente, 3) como as VPU podem ser empregadas para caracterizar parâmetros mecânicos das alvenarias?

Como forma de contribuir para avanços na área, o principal objetivo desta pesquisa é analisar o comportamento das ondas ultrassônicas em painéis de alvenarias com presença de fissuras na argamassa de revestimento, destacando indicadores e características na interpretação dos dados a fim de fornecer um padrão que possibilite a identificação da presença destes danos em painéis de alvenarias históricas.

\section{EDIFICAÇÃO EM ESTUDO}

A Igreja de Nossa Senhora da Expectação, primeira edificação do município de Icó, integra um dos mais de 300 imóveis tombados como patrimônio histórico pelo Instituto do Patrimônio Histórico e Artístico Nacional (IPHAN) em 1998. Construída em 1709, originalmente com o nome de Capela de Nossa Senhora do Ó, a edificação destaca-se por ser o templo mais antigo do município de Icó e por sua importância histórica, uma vez que a partir de 1709, a cidade teve seu início, com o crescimento do povoado em torno desta Igreja. Em 1736, a então Capela de Nossa Senhora do Ó, foi escolhida como a Igreja Matriz, título que detém até hoje; e como consequência disto, o então Arraial da Ribeira dos Icós elevou-se a categoria de vila (VIANA, 2011).

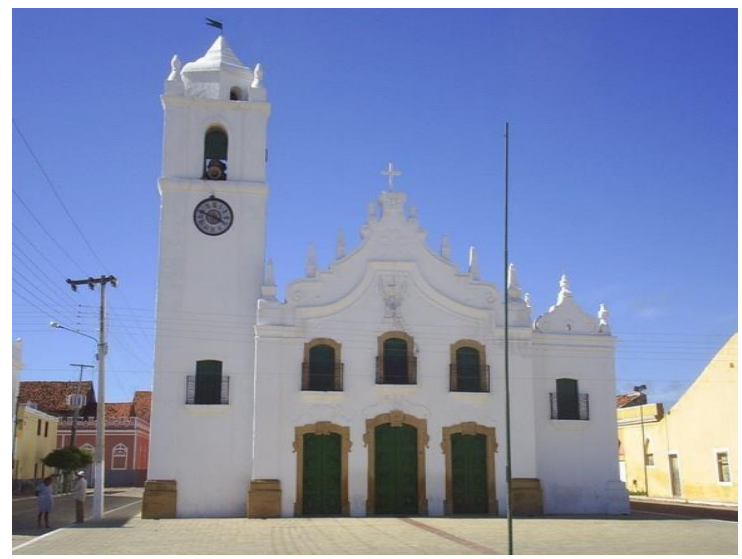

Figura 1: Fachada frontal, Igreja Nossa Senhora da Expectação

A Igreja possui $45.47 \mathrm{~m}$ de comprimento e $16.64 \mathrm{~m}$ de largura. Internamente, sua divisão abrange dez ambientes, conforme mostrado pela Figura 2. 

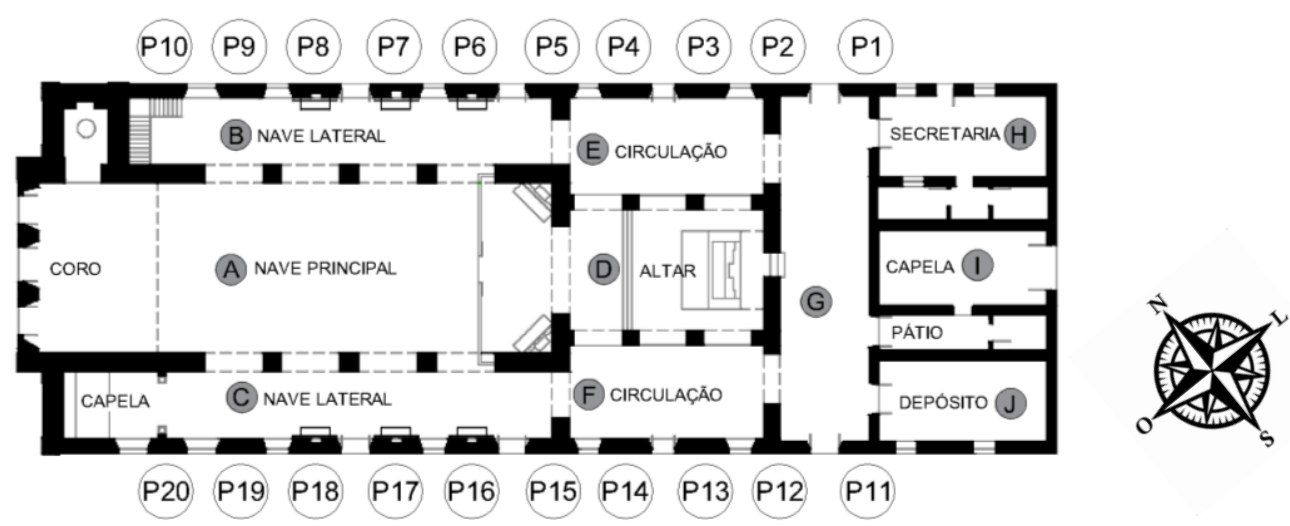

Figura 2: Planta baixa e indicação dos painéis

A geometria da igreja apresenta planta regular, composta pela Nave Principal, duas Naves Laterais, um altar Mor e as dependências da Sacristia. A igreja compõe-se de alvenarias de tijolos maciços, variando entre $46 \mathrm{~cm} \mathrm{e} 90 \mathrm{~cm}$ de largura, e foi construída utilizando-se técnicas vernaculares, com blocos de tijolos com valores dimensionais médios de 50 x 25 x $5 \mathrm{~cm}$ unidos entre si por uma argamassa de cal variante entre $1 \mathrm{~cm}$ e $1.50 \mathrm{~cm}$ de altura (C. Garcia, 2019). Na Figura 3, é possível identificar uma das laterais da igreja, onde pode-se localizar, em vermelho, os painéis de alvenaria escolhidos para aquisição de dados, estando estes localizados entre as esquadrias.
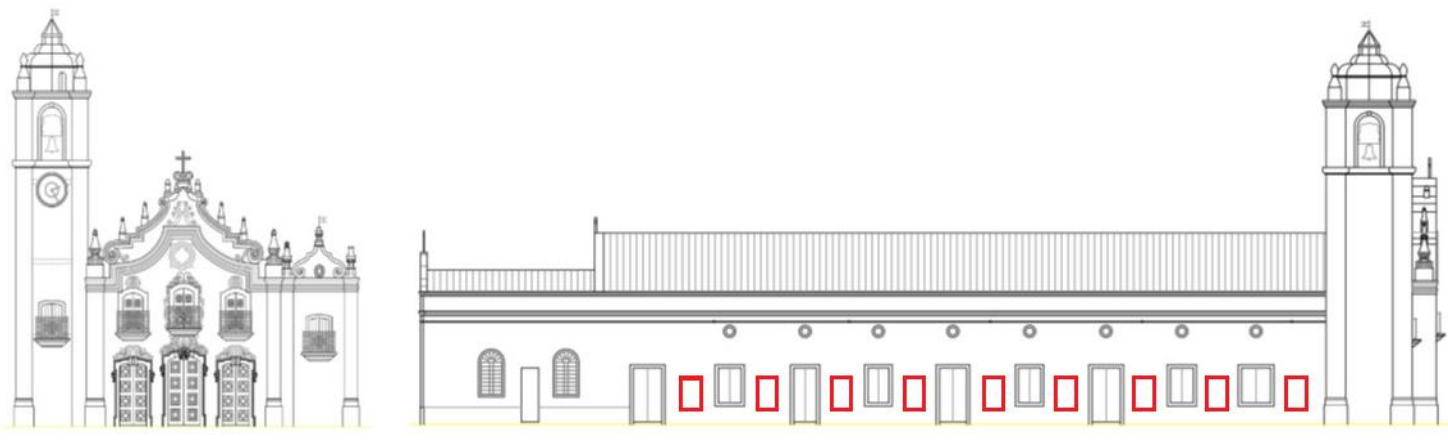

Figura 3: Fachada frontal e lateral, Igreja Nossa Senhora da Expectação

\section{METODOLOGIA}

O método ultrassônico consiste na transmissão e recepção de ondas sonoras de alta frequência (superior a 20.000 Hz) através de um material no qual deseja-se analisar. Essencialmente, os materiais são compostos por partículas, que no nível mais elementar são o Bóson de Higgs (P. W. Higgs 1966), com uma quantidade definida de energia que é transportada pelas ondas causando movimentos vibracionais. Nos sólidos, essas partículas apresentam um arranjo mais organizada devido ao fato de serem quase juntas umas das outras, mas ainda apresentando movimentos vibracionais. Portanto, pode-se notar que a velocidade do ultrassom dependerá, dentre outros fatores, do meio de propagação.

Para este estudo, os meios de propagação serão as estruturas de alvenaria: um conjunto de blocos de tijolos maciços assentados com argamassa de cal e revestimento com esta mesma argamassa (com espessura média de $1 \mathrm{~cm}$ ) e os possíveis elementos nela incorporados. Como a velocidade decresce rapidamente ao se propagar por meios líquidos, e mais ainda, em meios gasosos, é possível usar a velocidade média de propagação como estimativa da quantidade de vazios e, consequentemente, da densidade do material.

A ideia básica é fazer passar a onda ultrassônica por dentro do material, medindo-se o tempo de sua propagação até um outro ponto. Conhecido a distância entre os pontos dos quais foram realizados a transmissão e recepção da onda, é possível então determinar a velocidade média no trecho de propagação. Para tal utilizamos a equação 1 , onde $V$ é a velocidade de propagação da onda ultrassônica em m/s, $L$ é a distância entre a emissão e recepção da onda, em metros, e $t$ é o tempo em segundos.

$$
V=\frac{L}{t}
$$


Foi utilizado o equipamento Proceq ${ }^{\circledR}$ PUNDIT $2000 ® 54 \mathrm{KHz}$. O processamento de dados foi realizado com base nas recomendações da NBR 8802-2019. O método de transmissão do pulso ultrassônico indireto consistiu no modo de arranjo do transdutor-transmissor $(\mathrm{T})$ e do transdutor-receptor $(\mathrm{R})$, onde estes ficam posicionados na mesma face do material analisado, como pode ser observado pela Figura 4 a) e b).

a)

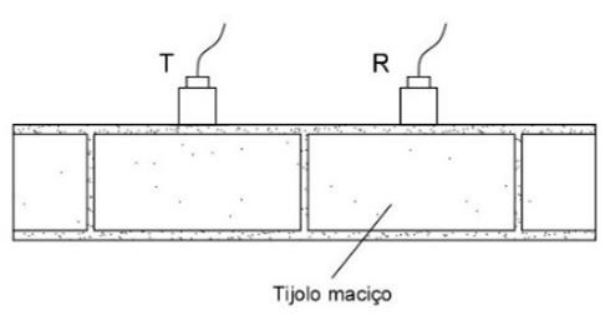

b)

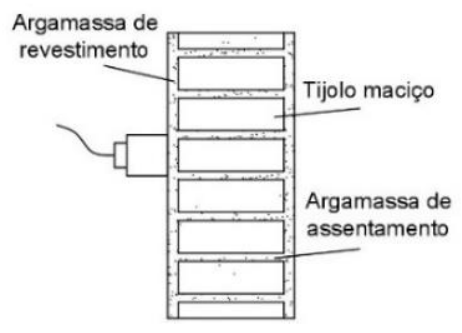

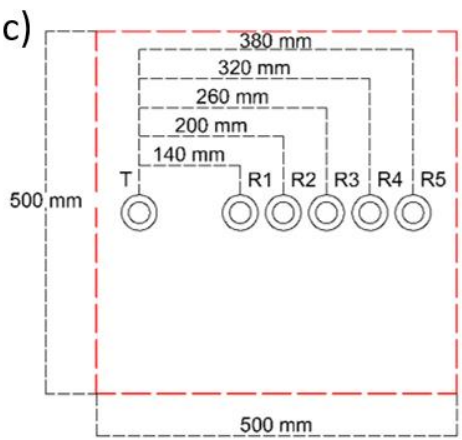

Figura 4: a) Vista superior, arranjo transdutor transmissor e receptor; b) Vista lateral, arranjo transdutor transmissor e receptor; c) Esquema de distancias das 5 medidas

Foram analisadas as paredes externas laterais da Igreja de Nossa Senhora da Expectação. Para tal, as fachadas laterais da edificação foram divididas em 20 painéis que tem configurações e geometria semelhantes. A localização de cada painel pode ser vista na Figura 2.

Foram selecionadas 16 dos 20 painéis para realização das medições ultrassônicos. Os painéis de alvenaria foram identificados entre P1-P20, localizadas nas laterais da igreja, de maneira que entre os painéis P1 a P10, estão à Noroeste da igreja, enquanto os painéis de P11 a P20 estão situados na lateral Sudoeste. Foi então empregado o método dos quadrantes de aquisição, proposto por Mesquita (2018). Cada quadro de aquisição de dados, com medidas de 50x50 cm, foi composto por 5 medidas (distribuídas no centro do quadro) com os receptores ultrassônicos espaçados de $60 \mathrm{~mm}$ uns dos outros na direção horizontal e o transdutor em um ponto fixo distante $140 \mathrm{~mm}$ do primeiro receptor, como mostrado na Figura 4 c).

Foram processados os dados dos 16 painéis, a fim de obter um comportamento padrão dos painéis. Outrossim, foram identificados in loco 2 painéis com fissuração superficial bastante visível na argamassa, esses dois foram os painéis P19 e P20, e o comportamento destes foram analisados e comparados em relação à média. Como resultados, foram destacados os padrões de comportamento das VPU que podem apontar para a presença de fissuras na argamassa de revestimento.

\section{RESULTADOS}

Os tempos de propagação foram processados de maneira a fornecer a velocidade média de propagação da onda em cada quadrante e posteriormente distribuídas nos painéis a eles pertencentes, de maneira a fornecer um mapa de velocidade em todos os painéis de alvenaria selecionados. As distribuições das velocidades em cada painel foram interpoladas a fim de obter superfícies de velocidades que mostram o arranjo desta de forma contínua no painel.

A média das velocidades ultrassônicas realizadas em todos os 16 painéis a $0,75 \mathrm{~m}$ de altura foi de $1052,16 \mathrm{~m} / \mathrm{s}$, enquanto as médias nas alturas de $1,25 \mathrm{~m}$ e $1,75 \mathrm{~m}$ foram 786,72 m/s e 726,31 m/s, respectivamente. Tendo como referência a média da velocidade ultrassônica em $0,75 \mathrm{~m}$, os valores das velocidades ultrassônicas em 1,25 m e 1,75 m apresentaram uma redução média de $25,23 \%$ e 30,97\%. Comportamento semelhante das velocidades ultrassônicas observadas em (MESQUITA et al., 2018) e (BINDA et al., 2001).

Esse comportamento ocorre diante de uma maior quantidade de esforços atuando sobre as partes mais baixas dos painéis, grande parte desses esforços é resultante do próprio peso da estrutura, resultando em uma zona com maior rigidez, e consequentemente, velocidade de propagação ultrassônicas mais elevadas, similarmente ao trabalho de Manning (2014). Dessa maneira, o comportamento geral para um painel deve apresentar uma diminuição das velocidades médias a medida em que os pontos de medição se elevam em altura. Este mesmo comportamento foi 
verificado por Mesquita (2018). Tal comportamento da média das VPU foi representado na forma de mapa de cores, com isolinhas. Esta técnica foi empregada a fim de se obter a forma geral do comportamento das VPU em painéis de alvenaria, possibilitando uma comparação com os painéis com fissuras na argamassa de revestimento. O mapa de comportamento característico das VPU para um painel bem aderido pode ser identificado na Figura 5. Logo, é possível identificar as velocidades médias presentes nos painéis, assim como a variação destas ao passo que se sobe no painel. Tomando este comportamento como padrão, é possível comparar com os demais painéis em que foram identificados com fissuras na argamassa de revestimento.

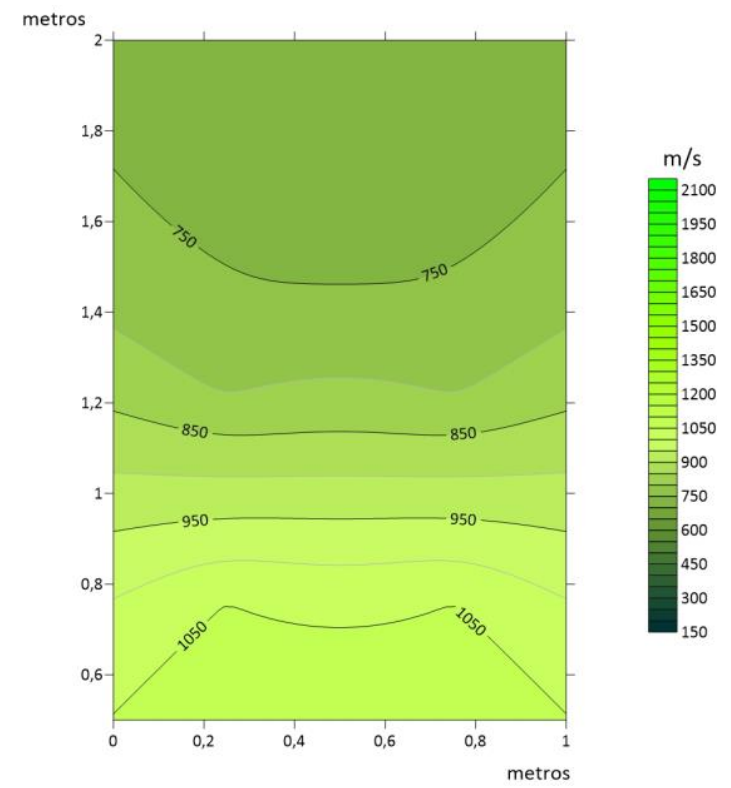

Figura 5: Mapa de velocidade padrão

Considerando o conjunto valores das velocidades ultrassônicas coletadas em cada painel de alvenaria durante os ensaios experimentais, e para indicar valores globais de cada um deles, foram calculadas e comparadas as velocidades ultrassônicas máxima, mínima, média e o desvio padrão entre elas, como pode ser analisado na Tabela 1. Com os dados da tabela, é possível identificar as variações obtidas para os diferentes painéis, e perceber que variam dentro da mesma faixa. Todavia, através destas variações, por si só, não se consegue detectar efeitos de destacamento ou fissuração. Para tal, faz-se necessário uma análise da distribuição dos padrões de comportamento pela superfície dos painéis, Figura 6.

Tabela 1 - Distribuição das velocidades $(\mathrm{m} / \mathrm{s})$ em cada painel com os respectivos dados estatísticos.

\begin{tabular}{c|c|c|c|c}
\hline Painéis & Máximo & Mínimo & Média & Desvio padrão \\
\hline P3 & 1400,5 & 388,3 & 788,4 & 356,4 \\
P4 & 1073,8 & 503,7 & 708,2 & 228,2 \\
P6 & 871,4 & 466,5 & 666,8 & 153,8 \\
P7 & 1268,6 & 417,5 & 713,7 & 309,5 \\
P8 & 1706,2 & 493,4 & 974,3 & 539,0 \\
P9 & 2017,6 & 490,2 & 1059,8 & 570,2 \\
P10 & 1629,2 & 621,4 & 1214,6 & 344,8 \\
P11 & 1387,4 & 794,7 & 1095,0 & 227,1 \\
P12 & 1700,5 & 854,3 & 1135,1 & 330,9 \\
P13 & 1229,7 & 737,8 & 904,5 & 177,0 \\
P14 & 1471,3 & 735,1 & 1096,1 & 254,0 \\
P16 & 1230,2 & 777,0 & 925,0 & 182,1 \\
P17 & 863,3 & 425,7 & 612,5 & 187,5 \\
P18 & 1425,3 & 290,7 & 682,8 & 438,2 \\
P19 & 1093,4 & 159,5 & 478,2 & 344,7 \\
P20 & 688,5 & 565,1 & 626,1 & 58,9 \\
\hline Média & 1316,1 & 545,0 & 855,1 & 293,9 \\
\hline
\end{tabular}

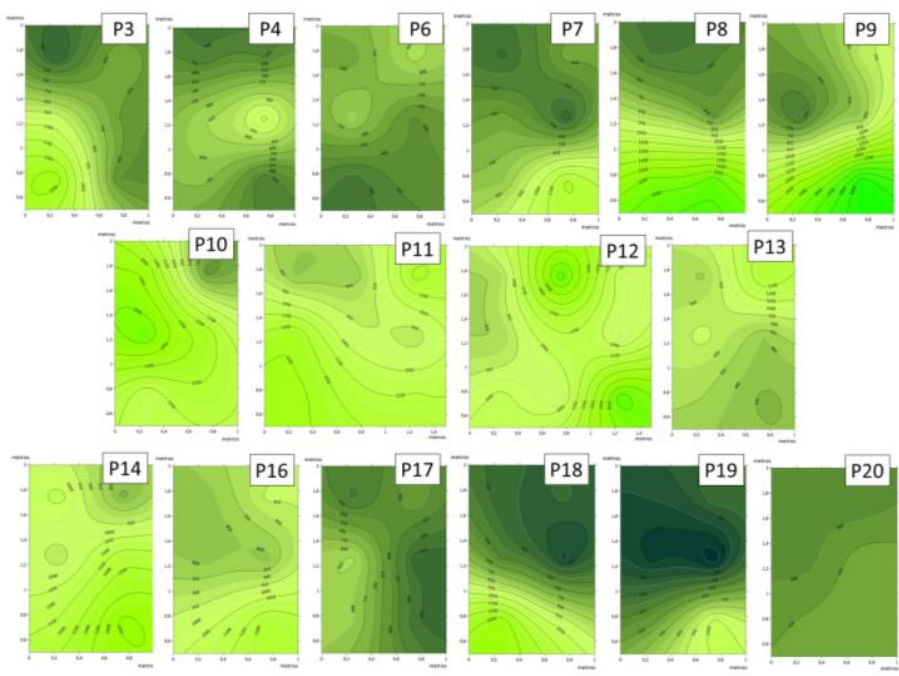

Figura 6: Visão geral, mapas de velocidades para todos os painéis 
Os painéis P18, P19 e P20, merecem uma maior atenção, uma vez que durante a aquisição dos dados foi verificada a presença de fissuras na argamassa de revestimento. A presença dessas fissuras foi identificada através de um ensaio à percussão, bem como por meio de uma inspeção visual, como pode ser verificado na Figura 7. Essas fissuras dificultaram um pouco a realização das leituras de maneira que para o painel P19, a leitura de alguns pontos tornou-se inviável e, portanto, a média do quadrante neste caso foi realizado apenas com 4 ou 3 valores de medição, ao invés dos 5 pontos.

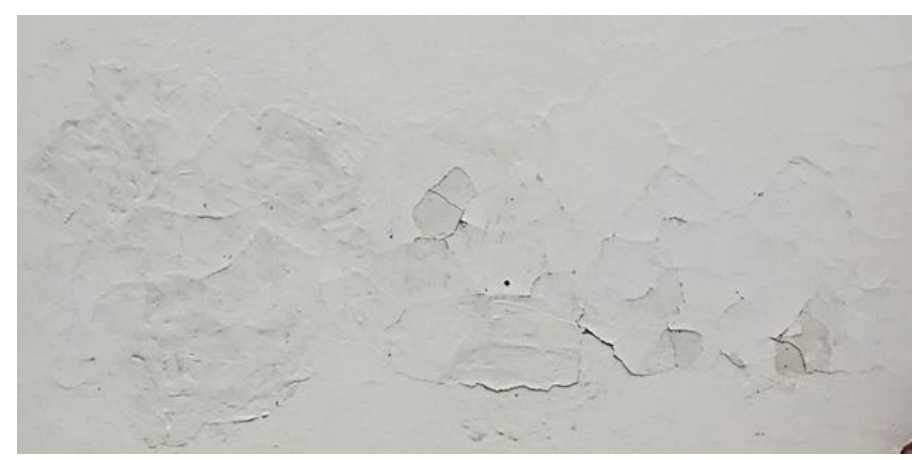

Figura 7: Painel P19 com a presença de fissuras na argamassa de revestimento

De modo geral, quando os painéis de alvenarias maciças de blocos cerâmicos estão com sua camada de revestimento bem aderidas, e quando estes não apresentam efeitos de confinamento, aberturas ou de elementos rígidos em sua proximidade, as VPU tendem a apresentarem valores maiores na região da base do painel, diminuindo gradativamente à medida em que o painel avança em altura. Admitindo-se que o revestimento esteja bem aderido, as VPU tendem a apresentar uma faixa de variação entre $1200 \mathrm{~m} / \mathrm{s}$ e $3000 \mathrm{~m} / \mathrm{s}$ nas alvenarias, variando nesta faixa em acordo com a densidade do material. Em alvenarias que utilizam cal em sua composição, estes valores tentem a estar mais próximos de $1200 \mathrm{~m} / \mathrm{s}$, enquanto em alvenarias de blocos maciços com argamassas de cimento, as VPU tendem a apresentar uma velocidade mais elevadas, próxima dos $3000 \mathrm{~m} / \mathrm{s}$. No entanto, nas argamassas de cal, as VPU tendem a se propagarem de modo mais devagar, entre 600 e 1000 m/s. Portanto, à medida em que a onda ultrassônica se propaga ao longo de um painel de alvenaria com revestimento bem aderido, maiores serão suas velocidades, enquanto que nos pontos em que há um destacamento do revestimento, a onda ultrassônica tende a ter velocidade de propagação mais próxima da faixa de variação da argamassa. Ainda há que notar, que a irregularidade nas camadas de argamassa de assentamento e presença de fissuras atenua ainda mais esta velocidade, sendo possível a obtenção de valores mais baixos ainda que os $600 \mathrm{~m} / \mathrm{s}$. Este entendimento quanto ao padrão de comportamento das VPU em alvenarias é observado quando são confrontados os trabalhos de Mesquita (2018), Manning et al. (2014) e Turgut et al. (2008).

Para o painel P18 foi verificado, de modo visual, apenas fissuração com aberturas inferiores a 3mm, numa pequena área do painel localizada próxima à cota 1,25m de altura. Essas fissuras são refletidas no padrão de comportamento das VPU no painel, onde se nota uma zona com velocidades mais baixas. Na Figura 8 é apresentado o mapa de velocidade para o painel P18, onde as cores mais claras indicam velocidade mais altas, enquanto as escuras indicam as baixas, conforme escala da Figura 8. Comparando as distribuições das VPU nos painéis P18 (Fig. 8) com o painel da Figura 5, é possível notar a grande diferença no comportamento de entre ambos. Primeiramente a falta de homogeneidade no painel P18, aponta para zonas de diferentes velocidades, tendo as velocidades mais baixas apenas em uma região do painel, indicando um comportamento anômalo localizado. 

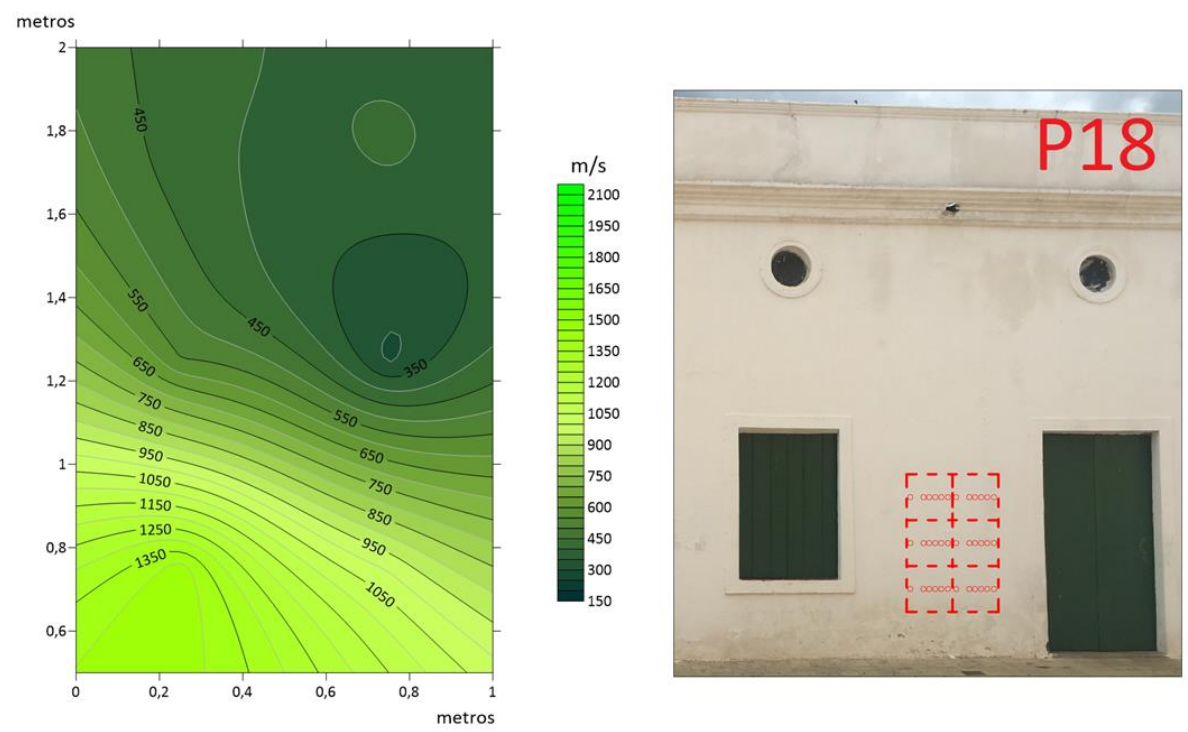

Figura 8: Mapa de velocidade para o painel P18 e sua posição relativa no painel de alvenaria

No painel P19 (Fig. 9), observou-se um comportamento bastante semelhante ao do painel P18 (Fig. 8). Foi verificado apenas uma fissuração localizada situada por volta da cota $1,25 \mathrm{~m}$ da altura. $\mathrm{Na}$ análise das distribuições das VPU no painel P19, foi verificado a existência de uma zona com velocidades mais baixas à altura de $1,25 \mathrm{~m}$, coincidente com a região de fissuração. A velocidade mínima encontrada neste painel foi de $159,49 \mathrm{~m} / \mathrm{s}$, a menor velocidade encontrada em todos os painéis analisados. A comparação entre o P19 (Fig. 8) e o painel padrão (Fig. 5) permite notar a falta de homogeneidade nas distribuições de VPU ao longo do P19, onde aponta-se para zonas de diferentes velocidades, associado a localização de baixas velocidades apenas em uma região do painel. Também de modo comparativo, pode-se observar que as variações das VPU no P19 são mais acentuadas que as variações identificadas no painel P18. Logo, esse comportamento que foge ao padrão de comportamento das ondas ultrassônicas em painéis de alvenaria é condizente com a zona onde foi identificado em loco com a presença de fissuras na argamassa de revestimento, conforme Figura 7.
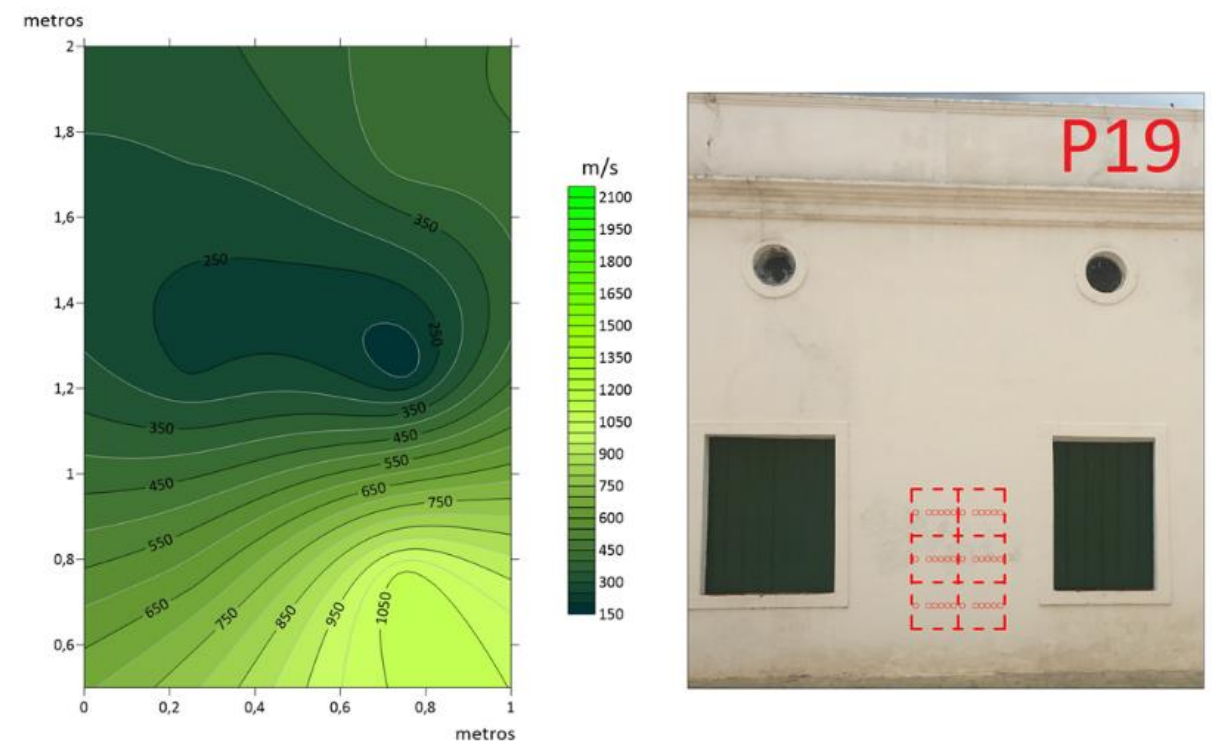

Figura 9: Mapa de velocidade para o painel P19 e sua posição relativa no painel de alvenaria

A distribuição das VPU ao longo do painel P20 (Fig. 10) também mostra um resultado heterogêneo aos demais, sendo também bastante diferente dos painéis P18 e P19. O painel P20 apresenta velocidades ultrassônicas quase que constante em toda sua extensão, com uma velocidade média de $626,11 \mathrm{~m} / \mathrm{s}$. Esse resultado é reflexo das fissuras generalizadas encontrada neste painel que se estendem por toda sua área. Nesta condição, é possível notar que a velocidade ultrassônica média do painel, de $626,11 \mathrm{~m} / \mathrm{s}$, condiz com a faixa de propagação das ondas ultrassônicas em argamassas 
cal. Analisando os valores das VPU medidas ao longo do painel e considerando a equação (1), os resultados mostram que as ondas se propagaram pela região superficial da argamassa, se propagando em linhas retas, de modo generalizado. $\mathrm{O}$ fato de as ondas percorrerem um caminho na superfície do revestimento indica que a argamassa não está bem aderida às alvenarias, resultando, portanto, em um comportamento constante das VPU em todo o painel. Ao analisar a Tabela 1, é possível notar que o painel P20 apresentou o menor máximo de velocidade entre os demais painéis, com apenas 689 $\mathrm{m} / \mathrm{s}$; outrossim apresentou um desvio padrão bem abaixo dos demais, com apenas $58,9 \mathrm{~m} / \mathrm{s}$, frente a média de 293,89 $\mathrm{m} / \mathrm{s}$.
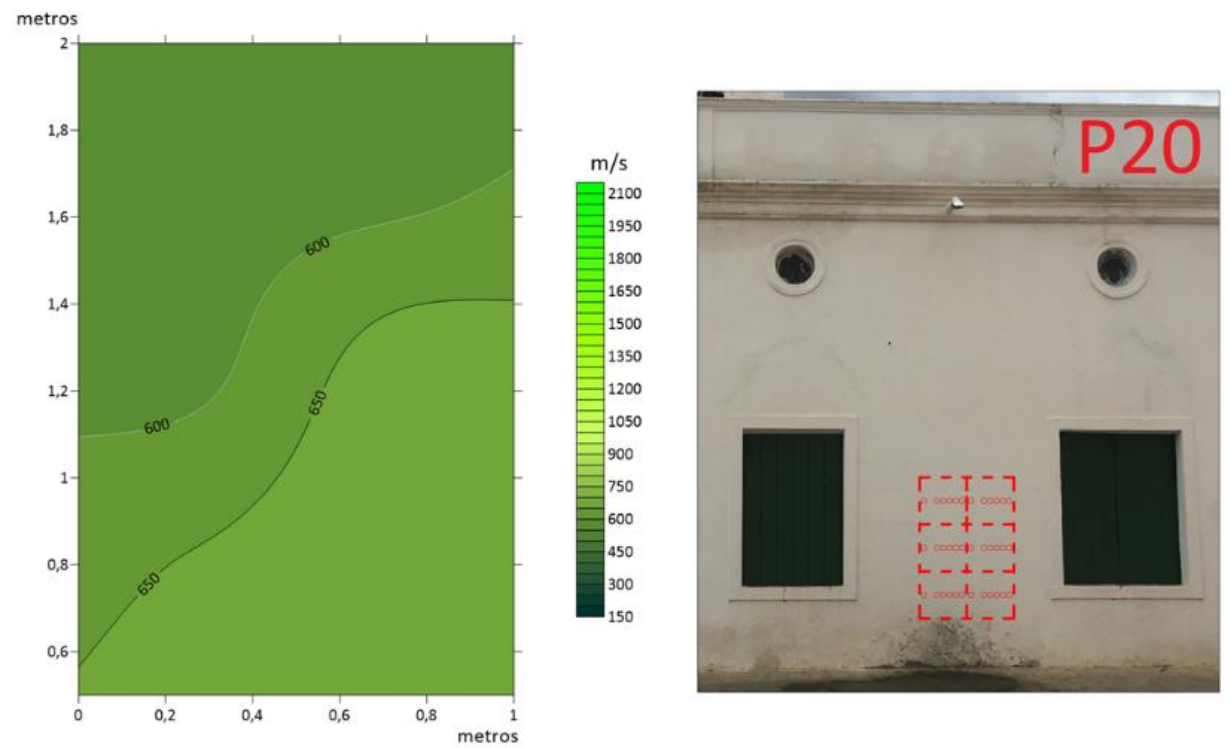

Figura 10: Mapa de velocidade para o painel P19 e sua posição relativa no painel de alvenaria

\section{CONCLUSÃO}

Considerando que cada material possui uma velocidade característica de VPU, variando de acordo com sua densidade e homogeneidade, a existência de danos ou estruturas distintas dos padrões do material analisado apresenta influência na VPU medida. Assim, a aplicação de VPU para se caracterizar as propriedades de alvenarias pode ser uma ferramenta de grande utilidade no processo e caracterização das construções históricas, quando identificados os padrões típicos de comportamos da onda ultrassônica. A identificação de padrões de propagação ultrassônica em alvenarias além de poder ser utilizado para a identificação de anomalias num painel, também pode servir como base para comparação da distribuição das VPU em longo das alvenarias de uma igreja, por exemplo, para indicar se todas as alvenarias apresentam método construtivo similar.

Os resultados deste trabalho indicam três comportamentos típicos de VPU em painéis de alvenarias, nomeadamente:

- Em painéis de alvenaria de tijolos maciços com argamassa de cal, e revestimento argamassado de cal, com espessura não superior a $1,5 \mathrm{~cm}$, quando não sob o efeito de confinamento, de elementos rígidos, ou sob o efeito de aberturas nas margens do painel, como janelas e portas, as ondas ultrassônicas apresentam velocidades de propagação maiores na base do painel, sendo sua velocidade decrescente à medida em que a altura avança;

- Para o caso de presença de fissuras não generalizadas nos revestimentos argamassados de cal em alvenaria de tijolos maciços assentados com argamassa de cal, as regiões com a presença de fissuradas apresentam velocidades de propagação mais próxima da faixa típica das VPU argamassas de cal (em torno dos $600 \mathrm{~m} / \mathrm{s}$ ou abaixo deste valor), sendo que as demais áreas do painel apresentam valores de VPU de acordo com o comportamento padrão de distribuição ultrassônica, conforme descrito no tópico anterior;

- A situação de fissuração generalizada e ausência de aderência nos revestimentos argamassados de cal em alvenaria de tijolos maciços assentados com argamassa de cal, faz com que as ondas ultrassônicas se propagem de modo quase constante, e apenas na superfície do revestimento, com valores característicos da VPU típico ao das argamassas de cal, essencialmente entre $600 \mathrm{~m} / \mathrm{s}$ e $1000 \mathrm{~m} / \mathrm{s}$, podendo estes valores serem atenuados pela presença de fissuras e vazios. 
Os diferentes comportamentos nos padrões de propagação ultrassônica em painéis de alvenaria, abrem a possibilidade para que as VPU possam ser aplicadas na caracterização de elementos heterogêneos, pois o comportamento das VPU ao longo de um painel pode ser bastante eficiente em localizar qualitativamente a presença de fissuras na argamassa, indicar seu descolamento ou indicar a boa qualidade do sistema argamassa-blocos de tijolos.

Por fim, este trabalho introduz uma nova visão na forma de interpretação dos resultados do ensaio ultrassônico, que ao longo das últimas décadas a literatura insistiu na observação dos valores das velocidades, sem consideração do padrão de distribuição. A observação de padrões de comportamento das VPU torna possível a caracterização de materiais heterogêneos, abrindo caminho para uma linha de estudos no âmbito das alvenarias, especialmente as históricas.

\section{AGRADECIMENTOS}

Os autores deste trabalho agradecem ao Laboratório de Reabilitação e Durabilidade das Construções (LAREB) pelos recursos mobilizados e pelo apoio durante a pesquisa, bem como a Universidade Federal do Ceará (UFC) por disponibilizar o equipamento e a estrutura técnica e laboratorial.

\section{REFERÊNCIAS}

A.B. de, N. ABNT, Técnicas, NBR 8802 - Concreto endurecido - Determinação da velocidade de propagação de onda. Brazil, p. 8, 1992.

ALVES, A. L. S. Proposição de um método de caracterização de alvenarias de edificações históricas por meio de avaliação ultrassônica Monografia, 2017.

BINDA, L.; SAISI, A.; TIRABOSCHI, C. Application of sonic tests to the diagnosis of damaged and repaired structures. NDT \& E International, v. 34, n. 2, p. 123-138, mar. 2001. https://doi.org/10.1016/S0963-8695(00)00037-2

BOSCATO, G. et al. Optimized procedures and strategies for the dynamic monitoring of historical structures. J Civil Struct Health Monit 6, 265-289, 2016. https://doi.org/10.1007/s13349-016-0164-9

C. G. Araújo, "Análise numérica de um patrimônio histórico em icó como auxílio ao monitoramento estrutural” Universidade de Fortaleza, 2018.

CERAVOLO, Rosario et al. Vibration-based monitoring and diagnosis of cultural heritage: a methodological discussion in three examples. International Journal of Architectural Heritage, n. June 2015, p. 375-395, 2014. https://doi.org/10.1080/15583058.2013.850554

FIGUEIREDO, E. P. Inspeção e Diagnóstico de Estruturas de Concreto com Problemas de Resistência, Fissuras e Deformações. In: ISAIA, G. C. (Ed.). Concreto: Ensino, Pesquisa e Realizações. São Paulo: IBRACON, 2005.

LORENZI. Utilização de ultra-som para o monitoramento de estruturas de concreto. Rio de Janeiro, 2013.

MANNING, E. et al. Direct Sonic and Ultrasonic Wave Velocity in Masonry under Compressive Stress. 9th International Masonry Conference, Guimarães, 2014.

MARTINI, R. Caracterização de alvenarias de granito baseada em técnicas geofísicas, mecânicas e redes neuronais. Tese de Doutorado em Engenharia Civil. Universidade do Porto. 2019.

MESQUITA, E. et al. Non-destructive characterization of ancient clay brick walls by indirect ultrasonic measurements. Journal of Building Engineering, v. 19, n. May, p. 172-180, 2018. https://doi.org/10.1016/j.jobe.2018.05.011

Mesquita, E., Martini, R., Alves, A. et al. Heterogeneity detection of Portuguese-Brazilian masonries through ultrasonic velocities measurements. J Civil Struct Health Monit 8, 847-856, 2018. https://doi.org/10.1007/s13349$\underline{018-0312-5}$ 


\section{CBPAT 2020 \\ CONGRESSO BRASILEIRO DE PATOLOGIA DAS CONSTRUÇÕES \\ DE 15 A 17 DE ABRIL | FORTALEZA - CE \\ ISBN 978-65-86819-05-2}

MESQUITA, et al. Long-term monitoring of a damaged historic structure using a wireless sensor network. Engineering Structures, v. 161, n. February, p. 108 - 117, 2018. https://doi.org/10.1016/j.engstruct.2018.02.013

MIRANDA, L.F.B. Ensaios acústicos e de macacos planos em alvenarias resistentes. Tese de Doutorado em Engenharia Civil. Faculdade do Porto. 259 p. 2011.

MUNICH RE. TOPICS GEO: Natural catastrophes 2015. Munich: MUNICH RE, 2016.

P.W.Higgs, Spontaneous symmetry breakdown without massless bosons, Phys. Rev. 145 (4), 1156-1163, 1966.

TURGUT, P. Properties of masonry blocks produced with waste limestone sawdust and glass powder. Journal of Building Engineering, v. 22, n. July, p. 1422-1427, 2008. https://doi.org/10.1016/j.conbuildmat.2007.04.008

VIANA, Francirton Josino. Icó: Seu patrimônio, conhecer e preservar. 23 f. TCC (Graduação) - Curso de História, Centro de Educação, Universidade Estadual da Paraíba, Campina Grande, 2011. 